\title{
Promotion of myelopoiesis in myelosuppressed mice by Ganoderma lucidum polysaccharides
}

\author{
Xiao-Ling Zhu ${ }^{1}{ }^{*}$, Ji-Hong Liu ${ }^{2}$, Wei-Dong $\mathrm{Li}^{1}$ and Zhi-Bin Lin ${ }^{1 *}$ \\ ${ }^{1}$ Department of Pharmacology, School of Basic Medical Science, Peking University Health Science Center, Beijing, China \\ ${ }^{2}$ Health and Medical Analysis Center, Peking University, Beijing, China
}

Edited by:

Michael Heinrich, University of London, UK

Reviewed by:

Michael Heinrich, University of London, UK

Keliang Xie, General Hospital of Tianjin Medical University, China M. Pilar Gómez-Serranillos,

Universidad Complutense, Spain

${ }^{*}$ Correspondence:

Xiao-Ling Zhu and Zhi-Bin Lin,

Department of Pharmacology, School

of Basic Medical Science, Peking

University Health Science Center,

Beijing 100191, China.

e-mail: xiaolingzhu88@yahoo.com.cn;

linzb@public3.bta.net.cn

\begin{abstract}
Our previous studies demonstrated that Ganoderma lucidum polysaccharides (GI-PS) exhibit potent immunomodulating effects. Immunomodulation plays an important role in hematopoiesis. To investigate the possible mechanism by which GI-PS promote myelopoiesis during myelosuppression induced by cyclophosphamide, mice were injected intraperitoneally (i.p.) once daily with $2.5 \mathrm{mg} / \mathrm{kg}$ of G/-PS for 10 days and were treated i.p. once daily with cyclophosphamide $(100 \mathrm{mg} / \mathrm{kg})$ on days 2 through 4 . In the present study in vivo and in vitro, we find that GI-PS selectively bind to bone marrow stromal cells, stimulate the secretion of hematopoietic growth factors, and enhance the clonogenic activities of hematopoietic and stromal cells to promote hematopoiesis in myelosuppressed mice.
\end{abstract}

Keywords: Ganoderma lucidum polysaccharides, myelosuppression, hematopoiesis

\section{INTRODUCTION}

Ganoderma lucidum (known in China as Lingzhi and in Japan as Reishi) is a fungus of the family Polyporaceae that is regarded by Chinese people as the "miraculous king of herbs" and has attained a reputation in the East as a beneficial herbal substance. Lingzhi was first indexed as a longevity-promoting and tonic herb of the non-toxic superior class in the Shen Nong's Materia Medica (206 BC-8 AD). In clinical trials, G. lucidum exhibits therapeutic efficacy in treating cancer, insomnia, chronic bronchitis, hepatitis, and leukopenia. Polysaccharides are one of the primary components of G. lucidum. Numerous studies have confirmed the immunoregulatory activities of Ganoderma lucidum polysaccharides (Gl-PS; Lin, 2005; Zhu and Lin, 2006; Zhao et al., 2010). Cyclophosphamide (Cy), a widely employed alkylating agent and a major constituent of combination chemotherapy regimens; it causes myelosuppression, which limits chemotherapy's dose intensification and precludes the administration of optimal treatments for cancer patients (Bear, 1986).

Prior research has demonstrated that immune cells, such as $\mathrm{T}$ and $\mathrm{B}$ lymphocytes, macrophages, and dendritic cells, regulate hematopoiesis. Many hematopoietic growth factors (HGF) are produced by immune cells (Wang et al., 2005). Some HGF are available for the clinical treatment of myelosuppression and anemia. However, the use of HGF promotes the entry of hematopoietic stem cells (HSCs) into the cell cycle, depleting the supply of HSCs and inhibiting the long-term reconstitution of hematopoiesis (Homung and Longo, 1992). Previous studies have indicated that clinical trials applying these growth factors, such as stem cell factor (SCF), interleukin-3 (IL-3), granulocyte colony-stimulating factor (G-CSF), and granulocyte-macrophage colony-stimulating factor (GM-CSF), for bone marrow recovery after chemotherapy may carry the risk of potentially stimulating the growth of remaining tumor cells (Pedrazzoli et al., 1995; Hassan and Zander, 1996; Gutschalk et al., 2006). The use of erythropoietin (EPO) is likely to be restricted in oncology because it increases the risk of death and serious cardiovascular events (Steinbrook, 2007). Therefore, it is necessary to search for compounds that promote hematopoiesis, enhance immunity, potentiate anticancer effects, and detoxify anticancer drugs. Polysaccharides isolated from mushrooms and plants may be a source of beneficial compounds, as they have been reported to induce hematopoiesis (Jin et al., 2003; Hatano et al., 2004; Liao et al., 2005).

Immunomodulation plays an important role in hematopoiesis. Our previous study indicated that $\mathrm{Gl}$-PS stimulate immune cells to secret cytokines, and restore the bone marrow cells (BMC) counts and peripheral hemograms reduced by $\mathrm{Cy}$. The beneficial effects induced by the Gl-PS treatment were not paralleled with any evident toxic or side effects. (Lin, 2005; Zhu et al., 2007). However, the effects of $\mathrm{Gl}$-PS on hematopoietic progenitor cells, bone marrow stromal cells (BMSC), secretion of hematopoietic regulation factors, apoptosis of the whole BMCs, and bonding pattern, is poorly understood. Therefore, we investigated the effects of Gl-PS on regulating hematopoiesis in myelosuppressed mice and explored their mechanism of regulation.

\section{MATERIALS AND METHODS ANIMALS AND DRUGS}

Male C57BL/6J mice (6-8 weeks old) from an inbred strain were purchased from the Department of Experimental Animals, Peking University Health Science Center (PUHSC), Beijing, China. 
The experiments for this study were carried out in accordance with the Care and Use of Experimental Animals Committee of PUHSC. G lucidum (Leyss. ex Fr.) Karst. (Lingzhi), cultivated on wooden logs, was obtained from the G. lucidum Production Base in Taining County, Fujian Province in China. The quality of G. lucidum fruit bodies was monitored by Professor Mao XiaoLan, a senior researcher of the National Institute of Microbiology and Microbiological Institute, China Academy of Science. The suitable G. lucidum strain that was selected for cultivation with wooden logs was Ga0801 (No. of strain), which was preserved by Professors Shu-Qian Lin and Sai-Zhen Wang of the Fuzhou Institute of Green Valley Bio-Pharm Technology in China and identified by DNA fingerprinting analysis. Gl-PS were isolated through boiling-water extraction of the fruit bodies of G. lucidum, followed by ethanol precipitation, dialysis, and protein depletion using the Sevag method. The component sugars and molecular weight distributions of the glycopeptides were determined by gel permeation chromatography (GPC) and high performance liquid chromatography (HPLC). The structures of the glycopeptides were detected by IR, ${ }^{1} \mathrm{HNMR}$, and ${ }^{13} \mathrm{CNMR}$. The isolated Gl-PS are peptide-bound polysaccharides and have a molecular weight of 584,900 , with a ratio of polysaccharides to peptides of $93.61 \%: 6.49 \%$. The polysaccharides consist of $\mathrm{D}$-rhamnose, $\mathrm{D}$-xylose, $\mathrm{D}$-fructose, $\mathrm{D}$-galactose, D-mannose, D-glucose, and uronic acid, with a molar ratio of 0.793:0.964:2.944:0.167:0.389:7.94:0.33. The glycoside linkage was primarily in the $\beta$-form, with minor $\alpha$-bonding. The peptides contain 16 amino acids (Asp, Thr, Ser, Glu, Gly, Ala, Cys, Val, Met, Ile, Leu, Phe, Lys, His, Arg, and Pro; Lin et al., 2003). The purity of the Gl-PS is $98 \%$, which was analyzed by HPLC. As a water-soluble powder, Gl-PS were dissolved in physiological concentrations of saline for in vivo experiments or in serum-free RPMI medium 1640 (Gibco Laboratories, Grand Island, NY, USA) for in vitro experiments, filtered through a $0.22-\mu \mathrm{m}$ filter and stored at $4^{\circ} \mathrm{C}$ for future use. Cy and 5-fluorouracil (5-FU, Shanghai Hualian Pharmaceutical Co. Ltd., Shanghai, China) were dissolved in sterilized saline before being injected to mice. Endotoxins in Gl-PS samples were assayed under endotoxin-free experimental conditions using a limulus amebocytes lysate chromogenic assay kit (Beijing BXGK Technology Development Co., Ltd., Beijing, China). The quantity of endotoxin in Gl-PS was less than $0.011 \mathrm{EU} / \mathrm{mg}$, indicating that endotoxin contamination in Gl-PS was negligible.

\section{LABELING OF GL-PS WITH FLUORESCEIN ISOTHIOCYANATE}

Fluorescein isothiocyanate (FITC)-Gl-PS were prepared using a modification of the method described previously (Thornton et al., 1996). In short, $20 \mathrm{mg}$ of Gl-PS or dextran (MW 70,000, Sigma, USA) were dissolved in $4 \mathrm{ml}$ of $0.1 \mathrm{M}$ sodium carbonate, $\mathrm{pH} 9.0$, mixed with $14 \mathrm{mg}$ of (FITC, Sigma Chemical Co., St. Louis, MO, USA), stirred at room temperature for $4 \mathrm{~h}$ while being protected from light and centrifuged $(10,000 \times g, 1 \mathrm{~min})$. The conjugated $G l$ PS were separated from the unbound dye by gel filtration using a Sephadex G-25 (Pharmacia, NJ, USA) column equilibrated with phosphate-buffered saline (PBS). The necessary elution fractions were collected. The concentration of FITC was determined spectrophotometrically at $492 \mathrm{~nm}$ by a FITC standard curve, and the polysaccharides concentration of elution fractions was determined using a standard curve of serial-diluted dextran using the phenol$\mathrm{H}_{2} \mathrm{SO}_{4}$ method. The concentration of FITC-Gl-PS was adjusted to $1 \mathrm{mg} / \mathrm{ml}$.

\section{INDUCTION OF MYELOSUPPRESSION AND TREATMENT REGIME}

Mice were divided into three groups: (1) untreated normal controls, (2) mice injected with Gl-PS $(2.5 \mathrm{mg} / \mathrm{kg}$ ), and (3) mice injected with a vehicle (equivalent volume of sterile physiological saline) as a negative control. Mice were administered Gl-PS or vehicle i.p. once daily for 10 consecutive days and were treated i.p. with Cy $(100 \mathrm{mg} / \mathrm{kg})$ once daily on days 2 through 4 .

\section{PREPARATION OF SPLENOCYTE-CONDITIONED MEDIUM, GL-PS-SPLENOCYTE-CONDITIONED MEDIUM, AND PHYTOHEMAGGLUTININ P-SPLENOCYTE-CONDITIONED MEDIUM}

Single-cell spleen suspensions were pooled in serum-free RPMI1640 medium (Gibco Laboratories, NY, USA) by filtering the suspension through stainless steel sieves (200 mesh) with the aid of a glass homogenizer to exert gentle pressure on the spleen fragments. The splenocytes $\left(1 \times 10^{7}\right)$ were cultured in complete RPMI-1640 medium without splenocyte-conditioned medium (SCM) or with Gl-PS-splenocyte-conditioned medium (Gl-PSSCM) at concentrations ranging from 25 to $200 \mu \mathrm{g} / \mathrm{ml}$, or with phytohemagglutinin (PHA) at a final concentration of $10 \mu \mathrm{g} / \mathrm{ml}$ phytohemagglutinin $\mathrm{p}$-splenocyte-conditioned medium (PHASCM). After $48 \mathrm{~h}$, the respective supernatants were collected and sterilized by filtration and stored at $-20^{\circ} \mathrm{C}$.

\section{HEMATOPOIETIC PROGENITOR COLONY-FORMING UNIT-GRANULOCYTE-MACROPHAGE, MULTIPOTENTIAL COLONY-FORMING UNIT-GRANULOCYTE, ERYTHROCYTE, MACROPHAGE, MEGAKARYOCYTE, AND ERYTHROID (BFU-E) COLONY-FORMING CELL ASSAY}

CFU-Mix, BFU-E, and colony-forming unit-granulocytemacrophage (CFU-GM) assays were performed as previously described (Wang et al., 2005). In brief, the culture system of CFU-GM consisted of $0.2 \mathrm{ml}$ of $0.3 \%$ agar, $0.5 \mathrm{ml}$ of horse serum (Hyclone Laboratories, Logan UT, America), $0.2 \mathrm{ml}$ of bone marrow-derived mononuclear cells (BM-MNC; $1 \times 10^{6}$ cells $/ \mathrm{ml}$ ), $0.2 \mathrm{ml}$ of various SCM or Gl-PS, and $0.9 \mathrm{ml}$ of RPMI-1640, which was plated in 24 -well plates $(0.5 \mathrm{ml} /$ well $)$. After 7 days of culture, the number of granulocyte and/or macrophage colonies containing $\geq 50$ cells was counted using an inverted microscope (Olympus, NY, USA). The total volume of the CFU-Mix and BFU-E culture systems was $2 \mathrm{ml}$, containing $10 \% 0.1 \mathrm{mM}$ 2-mercaptoethanol, $1 \% 2 \mathrm{mM}$ L-glutamine, $1 \%$ bovine serum albumin (BSA), $30 \%$ fetal calf serum (FCS), 2 units erythropoietin (EPO; Sigma, St. Louis, MO, USA), 20\% SCM, 10\% BM-MNC $\left(2.5 \times 10^{6}\right.$ cells $\left./ \mathrm{ml}\right)$, and $0.7 \mathrm{ml} 2.7 \%$ methylcellulose in Iscove's modified Dulbecco's medium (IMDM); this volume was plated into 96-well plates $(0.2 \mathrm{ml} /$ well). After seven to 10 days of culture, the number of BFUE colonies was counted. BFU-E colonies displayed a red color and burst. After 12 days of culture, the number of CFU-mix colonies was counted. The CFU-mix was identified by its ability to form a mixed colony in which reddish cells (erythroid cells) mixed with colorless cells (granulocytes, macrophage, and megakaryocyte). 


\section{HIGH PROLIFERATIVE POTENTIAL COLONY-FORMING CELLS ASSAY}

As described previously, 5-FU-resistant high proliferative potential colony-forming cells (HPP-CFCs) were assayed (Wang et al., 2005). The culture system consisted of $20 \%$ FCS, $10 \%$ BSA, $40 \%$ IMDM, $10 \%$ serum of aplastic anemia mice, $10 \% \mathrm{BMC}\left(10^{5}\right.$ cells $)$, and $10 \%$ agar $(33 \mathrm{~g} / \mathrm{L})$. After 14 days of culture, HPP-CFC were identified by their ability to form high proliferative potential colonies with diameters that were equal to or greater than $0.5 \mathrm{~mm}$.

\section{COLONY-FORMING UNIT-FIBROBLAST ASSAY AND PREPARATION OF CONDITIONED MEDIUM FOR BONE MARROW STROMAL CELLS}

The colony-forming unit-fibroblast (CFU-F) assay was carried out as previously described (Wang et al., 2005). A total of $1 \times 10^{6} \mathrm{BMC}$ were incubated in Dulbecco's Modified Eagle Medium supplemented with $10 \% \mathrm{FCS}, 10 \% \mathrm{SCM}$, and $1 \%$ penicillin-streptomycin at $37^{\circ} \mathrm{C}$ and $5 \% \mathrm{CO}_{2}$. At intervals of 4 days, the cell culture medium was replaced. After 10 days, the medium was removed, and the dishes were Wright-Giemsa stained. A fibroblast colony of greater than 20 cells was scored as a CFU-F. When BMSC achieved confluence, the confluent cell layers were washed twice with versene $\left(\mathrm{Ca}^{2+}\right.$ - and $\mathrm{Mg}^{2+}$-free $0.1 \%$ ethylenediaminetetraacetic acid (EDTA) in PBS]. Adherent BMSC were detached with $0.25 \%$ trypsin in versene and seeded at a density of $1 \times 10^{6}$ cells/well in 24-well microplates in complete RPMI-1640 medium with $\mathrm{Gl}$ PS $(25-200 \mu \mathrm{g} / \mathrm{ml})$ for $48 \mathrm{~h}$ or in an equal volume of serum-free RPMI-1640 as a control, and supernatants were collected and stored as small aliquots at $-20^{\circ} \mathrm{C}$ until use. On day 11 after $\mathrm{Gl}$-PS administration, $\mathrm{BMC}$ in myelosuppressed mice were removed to evaluate the in vivo effect of Gl-PS on CFU-F formation.

\section{CYTOKINE ASSAY}

Cytokines were measured using a sandwich enzyme-linked immunosorbent assay (ELISA) kit (R\&D systems, Minneapolis, MN, USA) according to the manufacturer's protocol.

\section{APOPTOSIS ASSAY}

Apoptosis of BMC was determined with an Annexin V-FITC Apoptosis Detection Kit I (Pharmingen, San Diego, CA, USA).

\section{STATISTICAL ANALYSIS}

Results were presented as means \pm SEM of six mice. One-way analysis of variance (ANOVA) followed by Dunnett's $t$-test was employed. $P$ values below 0.05 were considered significant.

\section{RESULTS \\ EFFECTS OF GL-PS ON THE CLONOGENIC ACTIVITY OF BONE MARROW-DERIVED HEMATOPOIETIC PROGENITOR CELLS AND STROMAL CELLS IN VITRO AND IN VIVO}

Our previous research indicated that, in Cy-induced myelosuppressed mice, chronic treatment with $G l$-PS (i.p., at $2.5 \mathrm{mg} / \mathrm{kg}$ ) resulted in the accelerated recovery of BMC and peripheral hemograms while enhancing the function of immune cells. No toxic or other side effects were observed in Gl-PS-treated mice during these experiments (Zhu et al., 2007). To explore the mechanism of action of Gl-PS, we designed experiments in vivo and in vitro. The results of the present study demonstrate that $\mathrm{Gl}$ PS $(2.5 \mathrm{mg} / \mathrm{kg})$ promote myelopoiesis in vivo in myelosuppressed mice, but that directly adding $\mathrm{Gl}$-PS $(25-200 \mu \mathrm{g} / \mathrm{ml})$ to cultures of various hematopoietic progenitor cells had no effect on colony formation (data not shown). However, the addition of Gl-PS to SCM increased colony-forming unit counts in vitro. Compared with the non-stimulation of normal SCM, Gl-PS-SCM treatment significantly promoted the colony formation of CFU-GM, CFUMix, BFU-E, and CFU-F, as observed in vitro (Figure 1). Gl-PS at a concentration of $100 \mu \mathrm{g} / \mathrm{ml}$ attained the maximal effect of Gl-PS-SCM on CFU-GM (Figure 1), which was higher than that of the positive control PHA-SCM. PHA-SCM is the source of colony-stimulating factors, which stimulate splenic mononuclear cells to secrete several HGF (Wang et al., 2005). Nevertheless, Gl-PS and normal SCM alone had no such colony-stimulating activity. After a 5-FU injection, only a 5-FU-resistant subset of resting stem cells, termed HPP-CFC, survived. Gl-PS, Gl-PS-SCM, and Gl-PSmedium for bone marrow stromal cells (BMSCM) alone failed to stimulate HPP-CFC formation in place of serum from aplastic anemia mice (data not shown). However, Gl-PS-SCM induced by Gl-PS synergized with the aplastic anemia serum to increased HPP-CFC counts (Figure 1). In an in vivo experiment, Gl-PS injection increased CFU-GM, BFU-E, CFU-Mix, and CFU-F counts in myelosuppressed mice on day 11 (Figure 2). These results suggest the presence of colony-stimulating factors in Gl-PS-SCM. Gl-PS promoted myelopoiesis through the indirect stimulation of HGF secretion, rather than direct stimulation of hematopoietic progenitor cell proliferation.

\section{CYTOKINES IN GL-PS-SCM, GL-PS-BMSCM, AND SERUM}

In in vitro experiments, the production of IL-1, IL-6, GM-CSF, and G-CSF in Gl-PS-SCM and Gl-PS-BMSCM induced by $G l$ PS for $48 \mathrm{~h}$ was significant higher than that of normal SCM. In

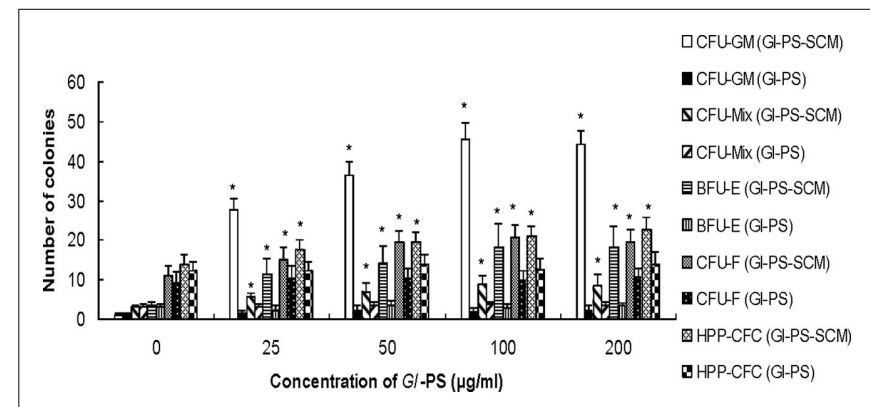

FIGURE 1 | Effect of GI-PS and GI-PS-SCM on the clonogenic activities of various hematopoietic progenitor cells and stromal cells in bone marrow in vitro. Splenocytes $\left(1 \times 10^{7}\right)$ were cultured in complete RPMI-1640 medium with G/-PS (GI-PS-SCM) at various concentrations $(0-200 \mu \mathrm{g} / \mathrm{ml})$ or with phytohemagglutinin (PHA) at a final concentration of $10 \mu \mathrm{g} / \mathrm{ml}$ (PHA-SCM). After $48 \mathrm{~h}$, the supernatants were collected for clonogenic assays. Bone marrow cells (BMC, $5 \times 10^{4} /$ well) were plated on CFU-GM, BFU-E, and CFU-Mix culture systems containing GI-PS $(0-200 \mu \mathrm{g} / \mathrm{ml})$ alone or Gl-PS-SCM induced by G/-PS $(0-200 \mu \mathrm{g} / \mathrm{ml})$. Colony numbers were counted (CFU-GM on day 7, BFU-E on day 7-10, and CFU-Mix on day 12). BMC $\left(10^{5}\right)$ were collected from 5-FU-treated mice and were cultured for 14 days in a HPP-CFC culture supplemented with $20 \%$ (v/v) GI-PS or GI-PS-SCM. ${ }^{*} P<0.05$ versus control (concentration of GI-PS: $0 \mu \mathrm{g} / \mathrm{ml}$ ). The colony-stimulating activities of PHA-SCM, which served as a positive control, were $31.4 \pm 4.5$ for CFU-GM, $12.1 \pm 2.6$ for BFU-E, $4.5 \pm 1.2$ for CFU-Mix, $16.2 \pm 4.0$ for CFU-F, and $21.2 \pm 3.5$ for HPP-CFC. 


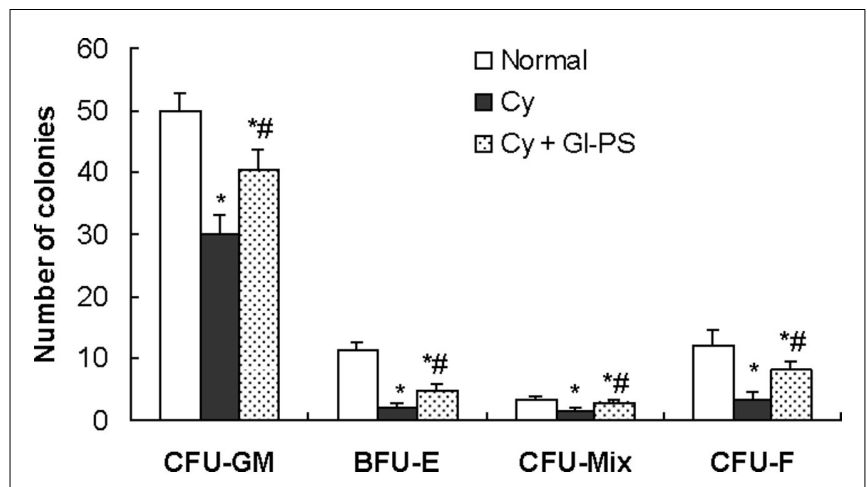

FIGURE 2 | Effects of GI-SP on the clonogenic activity of various hematopoietic progenitor cells and stromal cells in the bone marrow in vivo. On day 11 after $\mathrm{Cy}$ treatment, $\mathrm{BMC}\left(5 \times 10^{4}\right)$ were plated on CFU-GM, BFU-E, and CFU-Mix culture system. ${ }^{*} P<0.05$ versus the normal control; ${ }^{\#} P<0.05$ versus the vehicle-administered $C y$ group.

addition, an increase in SCF levels was observed in Gl-PS-BMSCM (Table 1). In in vivo experiments, Gl-PS injection increased the levels of IL- $1 \beta$, IL- 6 , G-CSF, and TNF- $\alpha$, which were undetectable in normal sera, and IFN- $\gamma$ in sera derived from myelosuppressed mice on day 11 (Table 2). Gl-PS stimulated the production of HGF, including G-CSF, GM-CSF, IL-1, and IL-6 from splenocytes and G-CSF, GM-CSF, IL-1, IL-6, and SCF from BMSC. These HGF primarily stimulate myelopoiesis (Wang et al., 2005). IL-3 was not detected in either Gl-PS-SCM or Gl-PS-BMSCM (data not shown), and SCF was undetectable in Gl-PS-SCM, which might be partially due to the absence of a Gl-PS receptor and/or production of IL-3 or SCF by the cells in culture. HPP-CFC formation requires the combined action of SCF, IL-3, GM-CSF, and G-CSF (Wang et al., 2005). The results suggested that the HGF contained in Gl-PS-SCM and Gl-PS-BMSCM synergized with the HGF contained in the serum of aplastic anemia mice to promote HPP-CFC formation. Gl-PS, normal SCM and BMSCM alone exhibited no such colony-stimulating activity.

The maintenance of hemopoiesis necessitates a balance between self-renewal and differentiation into mature blood cells. A class of cytokines involved in controlling this balance are the HGF, which stimulate the proliferation and maturation of progenitor cells. Hematopoietic inhibitors inhibit the proliferation of HSCs and progenitor cells, protect HSCs from excessive differentiation and maintain HSCs in G0/G1 cell cycle stage (Cheng and Wang, 2002). Studies indicate that HGF, such as IL-1, GM-CSF, and SCF, accelerate cell entry into $S$ phase, make hematopoietic cells more vulnerable to cytotoxic agents and cause the depletion of both the number and function of HSCs. Gl-PS injection increased TNF- $\alpha$ and IFN- $\gamma$ levels in sera from myelosuppressed mice (Table 2). We hypothesized that Gl-PS accelerate the recovery of myelopoiesis after chemotherapy by stimulating the secretion of IL-1, IL-6, G-CSF, GM-CSF, and SCF to promote hematopoietic precursor proliferation and differentiation and by upregulating negative regulators, such as TNF- $\alpha$ and IFN- $\gamma$, to prevent HSC cycling, resulting in HSC protection and inhibition of HSC depletion.
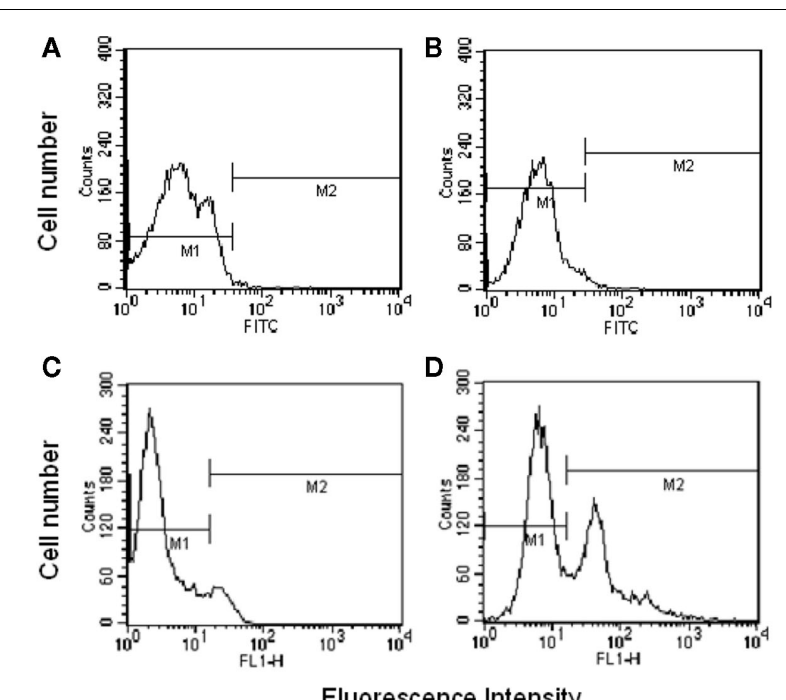

Fluorescence Intensity
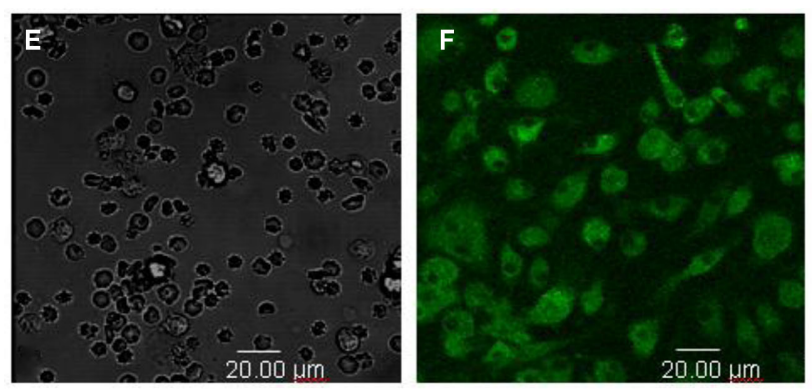

FIGURE 3 | Selective binding of FITC-GI-PS to BMSC. Non-adherent hematopoietic cells $(\mathbf{A}, \mathbf{B})$ and adherent $\operatorname{BMSC}(\mathbf{C}, \mathbf{D})$ were stained with FITC-Dextran [negative control (A,C)] or FITC-GI-PS (B,D) for flow cytometric analysis. Hematopoietic cells (E) and BMSC (F) stained with FITC-GI-PS were also observed under a confocal laser-scanning microscope.

\section{SELECTIVE BINDING OF GL-PS TO BONE MARROW STROMAL CELLS}

Bone marrow stromal cells and non-adherent cells were stained with FITC-Gl-PS for $1 \mathrm{~h}$ at $4^{\circ} \mathrm{C}$. Most of the adherent BMSC, but not non-adherent hematopoietic cells, were positively stained by FITC-Gl-PS (Figures 3A-F), suggesting that Gl-PS selectively bound to BMSC.

\section{EFFECT OF GL-PS ON BMC APOPTOSIS}

Bone marrow cells apoptosis was markedly increased after i.p., injection of Cy on day 5 during the treatment regime. No difference in BMC apoptosis was observed between the Gl-PS group and the vehicle group in myelosuppressed mice (Figure 4).

\section{DISCUSSION}

Blood cells and immune cells commonly originate in HSCs. BMSC possess immunoregulatory activity and are able to support hematopoiesis. Myeloid hematopoisis, lymphoid hematopoiesis, and immunoregulation adjacently exist in the hematopoietic inductive microenvironment (Wang et al., 2005). So 
Table 1 | Levels of hematopoietic growth factors in GI-PS-SCM and GI-PS-BMSCM.

\begin{tabular}{|c|c|c|c|c|c|}
\hline Concentration of $\mathrm{GI}-\mathrm{PS}(\mu \mathrm{g} / \mathrm{ml})$ & G-CSF & GM-CSF & IL-1 $\beta$ & IL-6 & SCF \\
\hline \multicolumn{6}{|l|}{ GI-PS-SCM } \\
\hline 0 & $0.0 \pm 0.0$ & $5.9 \pm 2.3$ & $12.7 \pm 4.8$ & $80.3 \pm 6.4$ & $0.0 \pm 0.0$ \\
\hline 50 & $634.8 \pm 82.1^{\mathrm{a}}$ & $26.7 \pm 4.9^{a}$ & $169.0 \pm 14.7^{a}$ & $439.8 \pm 41.0^{a}$ & $0.0 \pm 0.0$ \\
\hline 100 & $801.3 \pm 99.2^{\mathrm{a}}$ & $38.7 \pm 4.6^{a}$ & $281.4 \pm 22.5^{\mathrm{a}}$ & $635.7 \pm 77.0^{\mathrm{a}}$ & $0.0 \pm 0.0$ \\
\hline 0 & $8.0 \pm 3.1$ & $3.2 \pm 1.5$ & $5.3 \pm 3.1$ & $38.2 \pm 5.3$ & $20.3 \pm 4.1$ \\
\hline 25 & $20.8 \pm 4.8^{\mathrm{a}}$ & $11.5 \pm 2.4^{a}$ & $9.5 \pm 3.6$ & $155.7 \pm 6.9^{a}$ & $43.2 \pm 7.5^{a}$ \\
\hline 50 & $38.8 \pm 7.3^{\mathrm{a}}$ & $18.7 \pm 4.8^{\mathrm{a}}$ & $7.8 \pm 3.1$ & $298.8 \pm 15.2^{\mathrm{a}}$ & $76.0 \pm 10.7^{a}$ \\
\hline 100 & $71.2 \pm 11.2^{\mathrm{a}}$ & $49.2 \pm 10.3^{a}$ & $8.2 \pm 5.2$ & $797.0 \pm 33.3^{\mathrm{a}}$ & $92.5 \pm 13.6^{a}$ \\
\hline 200 & $101.7 \pm 20.5^{a}$ & $50.7 \pm 17.0^{a}$ & $9.0 \pm 4.9$ & $922.2 \pm 72.2^{\mathrm{a}}$ & $155.6 \pm 19.5^{\mathrm{a}}$ \\
\hline
\end{tabular}

Splenocytes $\left(1 \times 10^{7}\right)$ or bone marrow stromal cells $\left(1 \times 10^{6}\right)$ were cultured with GI-PS $(0-200 \mu \mathrm{g} / \mathrm{ml})$ for $48 \mathrm{~h}$. GI-PS-splenocyte-conditioned medium (GI-PS-SCM) and conditioned medium of bone marrow stromal cells (BMSCM) induced by GI-PS were collected to measure cytokines by ELISA.

${ }^{a} P<0.05$ versus control (concentration of GI-PS: $0 \mu \mathrm{g} / \mathrm{ml}$ ).

Table 2 | Comparison of serum cytokine concentrations (pg/ml) in naive and myelosuppressed mice treated with $\mathrm{Gl}-\mathrm{PS}$ (i.p., $2.5 \mathrm{mg} / \mathrm{kg}$ ) on day 11.

\begin{tabular}{lccccc}
\hline Groups & IL-1 $\beta$ & IL-6 & G-CSF & TNF- $\boldsymbol{\alpha}$ & IFN- $\boldsymbol{\gamma}$ \\
\hline Normal & $0.0 \pm 0.0$ & $0.0 \pm 0.0$ & $0.0 \pm 0.0$ & $0.0 \pm 0.0$ & $80.1 \pm 20.4$ \\
Cy + vehicle & $5.4 \pm 2.8^{\mathrm{a}}$ & $0.0 \pm 0.0$ & $70.5 \pm 18.5^{\mathrm{a}}$ & $0.0 \pm 0.0$ & $67.8 \pm 17.9$ \\
Cy + Gl-PS & $15.6 \pm 3.7^{\mathrm{b}}$ & $42.1 \pm 1.3^{\mathrm{b}}$ & $150.7 \pm 27.3^{\mathrm{b}}$ & $50.4 \pm 4.4^{\mathrm{b}}$ & $150.5 \pm 30.2^{\mathrm{b}}$
\end{tabular}

${ }^{a} P<0.05$ versus normal control and ${ }^{b} P<0.05$ versus vehicle control.

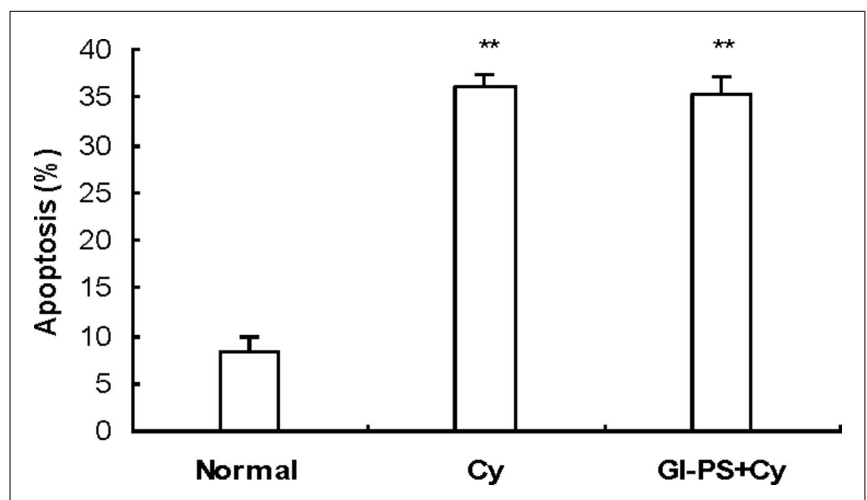

FIGURE 4 | Effect of GI-PS on apoptosis in BMC in myelosuppressed mice. BMC apoptosis was detected with an Annexin V-FITC test $24 \mathrm{~h}$ after i.p., injection of $\mathrm{Cy}$ on day 5 during the treatment regime. ${ }^{*} P<0.01$ versus normal.

immunomodulation is closely related to hematopoiesis. Myelosuppression and immunosuppression induced by chemoradiotherapy is a big problem restricting therapeutic effect of tumor. There is no ideal drug to solve it at present. Therefore, seeking the drugs that prevent and treat myelosuppression of chemoradiotherapy for enhancing the therapeutic effect and improving the prognosis, with no/low toxicity, is challenging.
Our previous studies showed that in cyclophosphamideinduced myelosuppressed mice, chronic treatment with low-dose Gl-PS resulted in accelerated recovery of BMC, red blood cells (RBC), and white blood cells (WBC), while enhancing function of immune cells (Zhu et al., 2007). In the present study, we found low-dose Gl-PS promoted myelopoiesis in vivo in myelosuppressed mice, but adding Gl-PS $(25 \sim 200 \mu \mathrm{g} / \mathrm{ml})$ to the colony culture of various hematopoietic progenitors directly, had no promotive effect on colony formation. However, addition of Gl-PS-SCM or Gl-PS-BMSCM increased colony formation of CFU-GM, CFU-Mix, and BFU-E in vitro. Our findings first demonstrated that most of the adherent BMSC but not nonadherent hematopoietic cells were positively stained by FITCGl-PS, so Gl-PS specifically bound to BMSC. BMSC not only provide the structural scaffolding for hematopoietic cell growth, but also secrete various HGF to stimulate hematopoiesis (Wang et al., 2005).

One observation showed that Ganoderma lucidum polysaccharide fraction (GLB) combined with 5-FU decreased the toxicity of 5-FU on BMCs (Liu et al., 2011). Several studies had reported that Gl-PS had significant effects on anti-radiation and leucopoiesis (Liu et al., 1985; Chen et al., 2000; Wu et al., 2003). In a stem cell expansion culture, polysaccharide fraction of G. lucidum (F3) possessed the thrombopoietin (TPO) and GM-CSF like functions to enhance the survival/renewal abilities of primitive hematopoietic stem/progenitor cells (Chen et al., 2010). A fraction (F3) of Reishi 
polysaccharides had been shown to activate the expression of IL-1, IL-6, IL-12, IFN- $\gamma$, TNF- $\alpha$, GM-CSF, G-CSF, and M-CSF in mouse splenocytes, and from this three subfractions had been prepared where F3G1 activates IL-1, IL-12, TNF- $\alpha$, and G-CSF, F3G2 activates all the cytokines as F3 does, and F3G3 activates only IL-1 and TNF- $\alpha$ (Chen et al., 2004).

Our research confirmed that CFU-F and CSF production in BMSC was significantly inhibited by $\mathrm{Cy}$, and $\mathrm{Gl}-\mathrm{PS}(2.5 \mathrm{mg} / \mathrm{kg}$, i.p.) significantly increased CFU-F formation in bone marrow from myelosuppressed mice. In our study, Gl-PS stimulated production of some HGF including G-CSF, GM-CSF, IL-1, and IL-6 from spleen cells and G-CSF, GM-CSF, IL-1, IL-6, and SCF from BMSC. These HGF mainly stimulate myelopoiesis.

Primitive hematopoietic stem cell (PHSC) and progenitor cells in bone marrow have an ability to proliferate and differentiate into mature blood cells. However, maintenance of haemopoiesis necessitates a balance between self-renewal on the one side, and differentiation into the various types of blood cell on the other. The cytokines involved in controlling this balance are HGF, which direct the division and maturation of the progenitor cells, and hematopoietic inhibitory factors, which inhibit PHSC and progenitor cells proliferation, protect $\mathrm{PHSC}$ from excessive differentiation in their expansive system, and keep them in $\mathrm{G}_{0} / \mathrm{G}_{1}$ cell cycle status (Cheng and Wang, 2002). Our experiments showed that low-dose injection of Gl-PS increased IL-1 $\beta$, IL-6, G-CSF, TNF- $\alpha$, and IFN$\gamma$ levels in sera from myelosuppression mice. We hypothesized that

\section{REFERENCES}

Bear, H. D. (1986). Tumor specific suppressor T-cells which inhibit the in vitro generation of cytolytic $\mathrm{T}$ cells from immune and early tumor bearing host spleens. Cancer Res. 46, 1805-1812.

Chen, H. S., Tsai, Y. F., Lin, S., Lin, C. C., Khoo, K. H., Lin, C. H., and Wong, C. H. (2004). Studies on the immunomodulating and anti-tumor activities of Ganoderma lucidum (Reishi) polysaccharides. Bioorg. Med. Chem. 12, 5595-5601.

Chen, J. J., Zhang, Y., Wang, X. M., Li, K. H., Liu, G. F., Wang, Q. C., Wu, X. P., and Lin, B. H. (2000). Studies on the pharmacological effects of the polysaccharides of Ganoderma lucidum II. The radiation-proof effect and elevating white blood cells action. Strait Pharm. J. 04, 15-17.

Chen, W. Y., Yang, W. B., Wong, C. H., and Shih, D. T. B. (2010). Effect of Reishi polysaccharides on human stem/progenitor cells. Bioorg. Med. Chem. 18, 8583-8591.

Cheng, L. M., and Wang, Q. R. (2002). Hematopoietic inhibitors elaborated by bone marrow endothelial cells. Zhongguo Shi Yan Xue Ye Xue Za Zhi 10, 485-491.

Gutschalk, C. M., Herold-Mende, C. C., Fusenig, N. E., and Mueller,

Gl-PS accelerated recovery of hematopoiesis after chemotherapy by promoting primitive and committed hematopoietic precursors proliferation induced by HGF secretion on the one hand, and on the other increasing negative regulatory factors such as TNF- $\alpha$ and IFN- $\gamma$ to prevent PHSC cycling resulted in protecting PHSC from damage.

In conclusion, rather than directly stimulating hematopoietic progenitor proliferation and inhibition of apoptosis in BMC, $\mathrm{Gl}$ PS promoted myelopoiesis by selective binding to BMSC which stimulated HGF secretion to enhance the clonogenic activity of hematopoietic progenitor cells and improving the hematopoietic microenvironment by enhancing CFU-F formation. Further research is necessary to determine whether Gl-PS promote myelopoiesis by preventing HSC cycling, thereby protecting them and enhancing the long-term reconstitution of hematopoiesis after Cy-induced myelosuppression.

Our findings may provide a mechanistic basis for using G. lucidum or Gl-PS as a possible alternative therapeutic means for lessening chemotherapy-induced myelosuppression via myelopoiesis potentiation, which needs further study and critical assessment.

\section{ACKNOWLEDGMENTS}

The authors thank Professor Shu-Qian Lin at the Fuzhou Institute of Green Valley Bio-Pharm Technology for generously providing Gl-PS.

extract from Lentinus lepideus. Exp. Biol. Med. 228, 759-766.

Liao, H. F., Chen, Y. J., and Yang, Y. C. (2005). A novel polysaccharide of black soybean promotes myelopoiesis and reconstitutes bone marrow after 5-flurouracil- and irradiation-induced myelosuppression. Life Sci. 77, 400-413.

Lin, S. Q., Wang, S. Z., Lin, Z. B., and Lin, Y.X. (2003). Isolation and identification of active components of Ganoderma lucidum cultivated with grass and wood $\log$ I. Extraction, purification and characterization of glycopeptide. Chin. Tradit. Herb. Drugs $34,33-35$.

Lin, Z. B. (2005). Cellular and molecular mechanisms of immunomodulation by Ganoderma lucidum. J. Pharmacol. Sci. 99, 144-153.

Liu, Y. F., Tang, Q. J., Zhang, J. S., Yang, Y., Zhou, S., Wu, D., Jia, W., and Feng, N. (2011). Monosaccharide composition analysis of two polysaccharide fractions from Ganoderma lucidum and their effects on inhibiting tumor growth in mice by 5 -fluracil. Food Sci. 11, 288-291.

Liu, Z. F., Chen, S. L., Yang, S. R., Chu, F., Luo, J., Deng, Z. M., and Chai, M. B. (1985). Studies of anti-radiation and leucopoietic activities of Ganoderma sinense polysaccharides. Jiangxi Sci. 01, 1-8.
Pedrazzoli, P., Bacciocchi, G., Bergamaschi, G., Cazzola, M., Danova, M., and Gibelli, N. (1995). Effects of granulocyte-macrophage colonystimulating factor and interleukin-3 on small cell lung cancer cells. Lung Cancer 12, 152-152.

Steinbrook, R. (2007). Erythropoietin, the FDA, and oncology. N. Engl. J. Med. 356, 2448-2451.

Thornton, B. P., Vetvicka, V., Pitman, M., Goldman, R. C., and Ross, G. D. (1996). Analysis of the sugar specificity and molecular location of the $\beta$-glucan-binding lectin site of complement receptor type 3 (CD11b/CD18). J. Immunol. 156, 1235-1246.

Wang, Q. R., Tan, M. Q., and Cheng, L. M. (2005). Hematopoietic Physiology, Chap. 6, 7 and 11. Changsha: Central South University Press.

Wu, J. Y., Chen, G. Y., Jiang, H. T., Hou, Y. R., and Zhang, Y. Q. (2003). Study on radioprotective and health care effect of Ganoderma lucidum polysaccharides mixture. J. Nanjing Norm. Univ. 3, 79-81.

Zhao, L. Y., Dong, Y. H., Chen, G. T., and Hu, Q. H. (2010). Extraction, purification, characterization and antitumor activity of polysaccharides from Ganoderma lucidum. Carbohydr. Polym. 80, 783-789. 
Zhu, X. L., Chen, A. F., and Lin, Z. B. (2007). Ganoderma lucidum polysaccharides enhance the function of immunological effector cells and hematopoiesis of immunosuppressed mice. J. Ethnopharmacol. 111, 219-226.

Zhu, X. L., and Lin, Z. B. (2006). Modulation of cytokines production, granzyme B and perforin in murine CIK cells by Ganoderma lucidum polysaccharides. Carbohydr. Polym. 63, 188-197.

Conflict of Interest Statement: The authors declare that the research was conducted in the absence of any commercial or financial relationships that could be construed as a potential conflict of interest.
Received: 06 December 2011; paper pending published: 04 January 2012; accepted: 07 February 2012; published online: 24 February 2012

Citation: Zhu X-L, Liu J-H, Li W$D$ and Lin Z-B (2012) Promotion of myelopoiesis in myelosuppressed mice by Ganoderma lucidum polysaccharides. Front. Pharmacol. 3:20. doi: 10.3389/fphar.2012. 00020
This article was submitted to Frontiers in Ethnopharmacology, a specialty of Frontiers in Pharmacology.

Copyright (C) 2012 Zhu, Liu, Li and Lin.

This is an open-access article distributed under the terms of the Creative Commons Attribution Non Commercial License, which permits non-commercial use, distribution, and reproduction in other forums, provided the original authors and source are credited. 